\title{
Audit of Anesthetic Equipment in Veterinary Clinics in Spain and Portugal
}

\author{
Jose I. Redondo ${ }^{1 *}$, Luis Domenech ${ }^{2}$, Cristina Mateu ${ }^{3}$, Alfon Bañeres ${ }^{3}$, Amalia Martínez $^{3}$ \\ and Diana Lopes ${ }^{4}$ \\ ${ }^{1}$ Departamento de Medicina y Cirugía Animal, Facultad de Veterinaria, Universidad Cardenal Herrera-CEU, CEU Universities, \\ Valencia, Spain, ${ }^{2}$ Departamento de Matemáticas, Física y Ciencias Tecnológicas, Escuela Superior de Enseñanzas Técnicas, \\ Universidad Cardenal Herrera-CEU, CEU Universities, Valencia, Spain, ${ }^{3}$ Ecuphar Veterinaria SLU, Barcelona, Spain, \\ ${ }^{4}$ Belphar Lda, Sintra, Portugal
}

OPEN ACCESS

Edited by:

Pablo E. Otero,

Universidad de Buenos

Aires, Argentina

Reviewed by:

Joao Henrique Neves Soares,

University of California, Davis,

United States

Louise Clark,

Davies Veterinary Specialists, United Kingdom

*Correspondence:

Jose I. Redondo

nacho@uchceu.es

Specialty section:

This article was submitted to

Veterinary Surgery and

Anesthesiology,

a section of the journa

Frontiers in Veterinary Science

Received: 07 August 2020 Accepted: 02 December 2020 Published: 21 December 2020

Citation:

Redondo JI, Domenech L, Mateu C, Bañeres A, Martínez A and Lopes D (2020) Audit of Anesthetic Equipment in Veterinary Clinics in Spain and Portugal. Front. Vet. Sci. 7:592597. doi: 10.3389/fvets.2020.592597
The objective of this retrospective study was to review the results of a 4-year audit performed on anesthetic machines and vaporizers used in veterinary clinics in Spain and Portugal. Data was collected between July 2016 and April 2020. Inspections were carried out by a team of seven veterinarians, using a human-modified system of checks that was adapted to a veterinary practice. The evaluation of each item was noted as "correct" or "incorrect". The vaporizers' performance was evaluated using a self-calibrating gas analyzer. The vaporizer was classified as "correct" or "incorrect" when the vaporization error was less than or equal to, or more than $20 \%$, respectively. The anesthetic machine was classified as "conforming" if all its components were noted as "correct" and no leaks were detected, or as "non-conforming" if any of the components was noted as "incorrect" or if a leak was detected. If the inspector was able to repair on-site the item malfunctions detected and the machine was fit for use, they issued a final report as "conforming." On the contrary, if such malfunctions persisted, the final report was "non-conforming," and a recommendation to remove the machine from service until its final repair was provided. To perform statistical analysis, each inspected item was used as predictor, classification and regression trees were built, and a random forest analysis was performed. A total of 2,001 anesthetic machines and 2,309 vaporizers were studied. After inspection, 42.7 and $26.4 \%$ of the machines were non-conforming and conforming, respectively, whereas $30.9 \%$ could be repaired in situ. A total of $27.1 \%$ of the isoflurane vaporizers and $35.9 \%$ of the sevoflurane vaporizers were incorrect. Machine learning techniques showed that the most important variables in the classification of the anesthetic machines as conforming or non-conforming were mostly the scavenger system and the canister, followed some way behind by the APL valve, source of oxygen, reservoir bag, vaporizer, and connections.

Keywords: anesthesia, veterinary, equipment malfunction, safety, anesthetic machine, vaporizer, audit, retrospective study 


\section{INTRODUCTION}

Modern anesthesia workstations are an integration of several components required to safely administer anesthesia to a patient. They consist of the anesthetic machine, vaporizers, ventilator, breathing systems, scavenging system, and monitors. Medical gases (i.e., air, oxygen, nitrous, oxide) are supplied through central units or oxygen concentrators, pipeline systems, terminal units, and hoses that connect these to the anesthesia machine. Breathing systems connect the anesthetic machine to the patient and dispense a controlled composition of medical gas mixture (1). Although many current anesthetic workstations include numerous safety mechanisms such as safety self-checks or oxygen failure safety devices, older and simpler anesthetic machines are still in use in a considerable number of Spanish and Portuguese veterinary clinics.

It has been widely demonstrated in human medicine that the malfunctioning of anesthetic equipment can lead to severe complications and fatal outcomes (2-5). Some reports on equipment failure resulting in complications have also been published in veterinary medicine (6-8). Interestingly, and although human safety guidelines establish protocols for routine inspection of anesthetic machines (9-11), a research study performed in France concluded that most equipment malfunctions were due to lack of routine maintenance (3).

Unlike in human medicine, veterinary clinics in Spain and Portugal are not obliged to follow safety protocols in regard to the anesthetic equipment, and these remain mere recommendations for a safe practice. To the Authors' knowledge, the only audit of veterinary anesthetic equipment to date was performed in New Zealand, it was published in 1995, and detected that 91\% of anesthetic machines were faulty (12). Therefore, the objective of this retrospective study was to review the results of a 4-year audit performed on anesthetic machines and vaporizers used in veterinary clinics in Spain and Portugal, that had a contract with two pharmaceutical companies.

\section{MATERIALS AND METHODS}

Anesthetic machines, vaporizers and other anesthetic equipment from veterinary clinics that had a commercial relationship with two veterinary pharmaceutical companies (i.e., Ecuphar Veterinaria in Spain and Belphar Lda. in Portugal) and that were inspected between July 2016 and April 2020 were analyzed in this report. Data collection included date of inspection, name and address of the clinic, and the name of the veterinarians who commonly used the anesthetic equipment. However, this data was partially anonymized for privacy, in accordance with the General Data Protection Regulation EU 2016/679 (13), and only date and province in which the inspection was performed was noted.

Inspections were carried out by a team of seven veterinarians experienced in clinical anesthesia, employees of the aforementioned companies, who had additionally received a specialized training in anesthetic equipment. The inspection team developed its own checking-up protocol based on the guidelines of the Sociedad Española de
Anestesiología y Reanimación (14) and adapted it to a standard veterinary practice.

Firstly, the anesthetic machine was inspected, beginning with a visual evaluation that consisted of noting its brand and model, absence or presence of components, state of conservation, location within the clinic and marks of previous revisions. Additionally, the main user of the machine was asked if leaks, component malfunctions, excessive consumption of oxygen or anesthetic agent, or any notable adverse events were detected during use.

Secondly, each item of the anesthetic machine was inspected and classified as "correct" or "incorrect." Detected failures were noted and repaired on site, if possible, in which case the item was reclassified (Table 1). The type of oxygen source (i.e., cylinder or concentrator) available was noted, connected, and checked. The oxygen concentration provided by the concentrator was evaluated using a Dräger VAMOS anesthetic gas analyzer (Drägerwerk AG \& Co. KGaA, Lübeck, Germany). Connections, pressure gauges and pressure reducing valves, flowmeters, adjustable pressure limiting (APL) valve, and oxygen emergency valve were inspected. The canister and the soda lime were visually inspected. Then, a leak test was performed. The corrugated tubes and the reservoir bag were attached correspondingly, another reservoir bag was placed at the connection to the endotracheal tube, and the APL valve was closed. Then, a fresh gas flow of 1-2 $\mathrm{L} / \mathrm{min}$ was provided until the pressure gauge of the system indicated $30 \mathrm{~cm} \mathrm{H}_{2} \mathrm{O}$. Then, the flow was interrupted, and the pressure gauge visualized to ensure the pressure was maintained. In the case of a decrease in pressure, the flow required to maintain $30 \mathrm{~cm}$ of $\mathrm{H}_{2} \mathrm{O}$ of pressure was recorded to quantify the leak and this number noted as the total leakage of the system. In accordance to standard recommendation (15), a maximum of 0.3 $\mathrm{L} / \mathrm{min}$ was considered acceptable. Location of the leak involved the hearing of an audible sound or the use of a leak detection spray, and these were fixed if possible. Availability of reservoir bags in different sizes and their quantity was also noted and finally, other anesthesia breathing systems (i.e., Mapleson A, D, and E) were also inspected.

Thirdly, the type of scavenging system was noted, and each item evaluated (Table 1). If passive systems (activated charcoal canisters) were used, they were weighed to determine their degree of saturation. If an anesthetic gas scavenging system (AGSS) was in use, the suction rate was checked.

Then, vaporizers' performance was evaluated using a Dräger VAMOS anesthetic gas analyzer (Drägerwerk AG \& Co. KGaA, Lübeck, Germany). This analyzer, which has a self-calibration system, has a measurement range of $0-8.5 \%$ for isoflurane and $0-10 \%$ for sevoflurane, with a precision of one decimal place and an anesthetic agent accuracy $\pm(0.2 \mathrm{vol} \%+15 \%$ relative $)$. In addition, this analyzer was periodically calibrated following manufacturer's recommendations. The inhalant anesthetic agent used in the agent-specific vaporizers, whether isoflurane or sevoflurane, was noted. A system that consisted of an airway adapter, a filter, and a sampling line connected to the gas analyzer was used for sidestream analysis. Depending on the machine analyzed, the inspector selected the location where to take the sample from (i.e., the vaporizer outlet, the fresh gas outlet, or 
TABLE 1 | List of items inspected, possible failures detected during inspection, their classification as repairable in-situ and by which method they could be repaired.

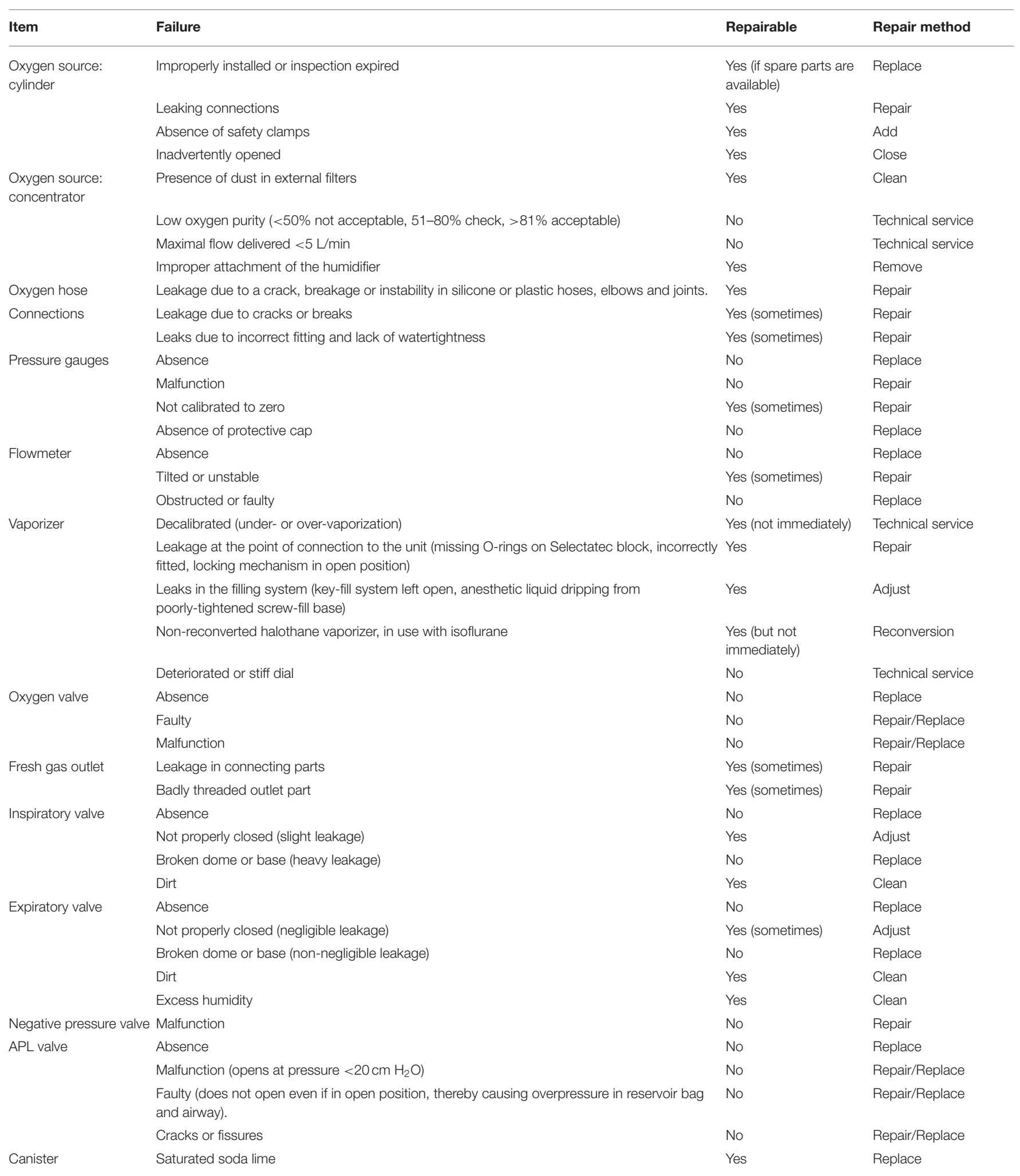


TABLE 1 | Continued

\begin{tabular}{|c|c|c|c|}
\hline Item & Failure & Repairable & Repair method \\
\hline & Excess or shortage of soda lime & Yes & Adjust \\
\hline & Leakage due to lack of O-rings at the base or top & $\begin{array}{l}\text { Yes (if spare parts are } \\
\text { available) }\end{array}$ & Repair \\
\hline & Leakage due to dirt or soda lime in the junctions & Yes & Clean \\
\hline & Leakage due to cracks or fissures (heavy leakage) & No & Replace \\
\hline \multirow[t]{3}{*}{ Corrugated tubes } & Deteriorated (dirt, fungus, moisture) & No & Replace \\
\hline & Cracked or broken & No & Replace \\
\hline & Lack of availability of several sizes (at least two between the neonatal, pediatric and adult units) & No & Replace \\
\hline \multirow[t]{2}{*}{ Reservoir bag } & Perforated & $\begin{array}{l}\text { Yes (if spare parts are } \\
\text { available) }\end{array}$ & Replace \\
\hline & Lack of availability of several sizes (a range of sizes between $0.5,1,2,3,4 \mathrm{~L}$ are advisable) & No & Replace \\
\hline \multirow[t]{2}{*}{ Mapleson A } & Deteriorated (dirt, fungus, moisture) & No & Replace \\
\hline & Cracked or broken & No & Replace \\
\hline \multirow[t]{3}{*}{ Mapleson D } & Fitted the wrong way (inspiratory branch in the expiratory part and vice versa) & Yes & Change position \\
\hline & Deteriorated (dirt, fungus, moisture) & No & Replace \\
\hline & Cracked or broken & No & Replace \\
\hline \multirow[t]{3}{*}{ Mapleson E } & Absence & No & Replace \\
\hline & Open bag system, no APL valve or waste gas collection & $\begin{array}{l}\text { Yes (if spare parts are } \\
\text { available) }\end{array}$ & $\begin{array}{l}\text { Install valve and a } \\
\text { closed reservoir bag }\end{array}$ \\
\hline & Cracked or broken & No & Replace \\
\hline \multirow[t]{4}{*}{ Scavenger system } & Missing device & Yes & Install \\
\hline & Collection only post-APL but not post-ventilator & Yes & Install \\
\hline & Active absorption system malfunction & No & Technical service \\
\hline & Saturated activated charcoal & $\begin{array}{l}\text { Yes (if spare parts are } \\
\text { available) }\end{array}$ & Replace \\
\hline
\end{tabular}

the Y piece). The measured vaporization (M) displayed on the analyzer was compared to three selected vaporization percentages (i.e., $0.5,2$, and $3 \%$ ) on the vaporizer dial (V) at four different fresh gas flows (i.e., $0.5,1,2$, and $3 \mathrm{~L} / \mathrm{min}$ ). The vaporization error (E) was calculated as $\mathrm{E}=(\mathrm{M}-\mathrm{V}) / \mathrm{V}$. The vaporizer was classified as "correct" or "incorrect" when E was less than or equal to, or more than $20 \%$, respectively (16). The vaporization data obtained at $0.5 \%$ were recorded but excluded from the final classification of the machine.

The anesthetic machine was classified as "conforming" if all its components were noted as "correct" and no leaks were detected, or as "non-conforming" if any of the components was noted as "incorrect" or if a leak was detected. If the inspector was able to repair on-site the item malfunctions detected and the machine was fit for use, they issued a final report as "conforming." On the contrary, if such malfunctions persisted, the final report was "non-conforming," and a recommendation to remove the machine from service until its final repair was provided.

\section{Statistical Analysis}

The statistical language R 4.0.2 was used. Firstly, a descriptive study of data was carried out. Parametric variables are shown as mean \pm standard deviation. Non-parametric numerical variables are shown as median and interquartile range. Qualitative variables are expressed as number of observations and frequency tables. Secondly, machine learning analysis, such as classification and regression trees and random forest analysis were performed to study the outcome of the inspection (conforming/nonconforming), using the result of the inspection of each part of the anesthetic machine (correct/incorrect) as predictors.

\section{RESULTS}

A total of 573 veterinary clinics from Spain and 119 from Portugal participated in this study, and 2,001 anesthetic machines and 2,309 vaporizers were inspected (Figure 1). The median number of the machines studied by province was 11 . The provinces in which most inspections were made were Barcelona (438), Madrid (139), the Balearic Islands (162), and Lisbon (105). Only three Spanish provinces (Avila, Segovia and Melilla) and three Portuguese provinces (Azores, Evora, and Portalegre) had no inspections performed.

At initial evaluation, 528 machines (26.4\%) and 1,473 (73.6\%) were classified as conforming and non-conforming, respectively. The median (range) of incorrect items detected in nonconforming machines was 2 (1-11). One incorrect item was detected in 527 machines, 2 in 416, 3 in 258, 4 in 143, 5 in 58 , and 6 or more in 71 . Out of the 1,473 machines initially classified as non-conforming, the inspector was able to repair 619 machines (30.9\%), which were therefore reclassified as 

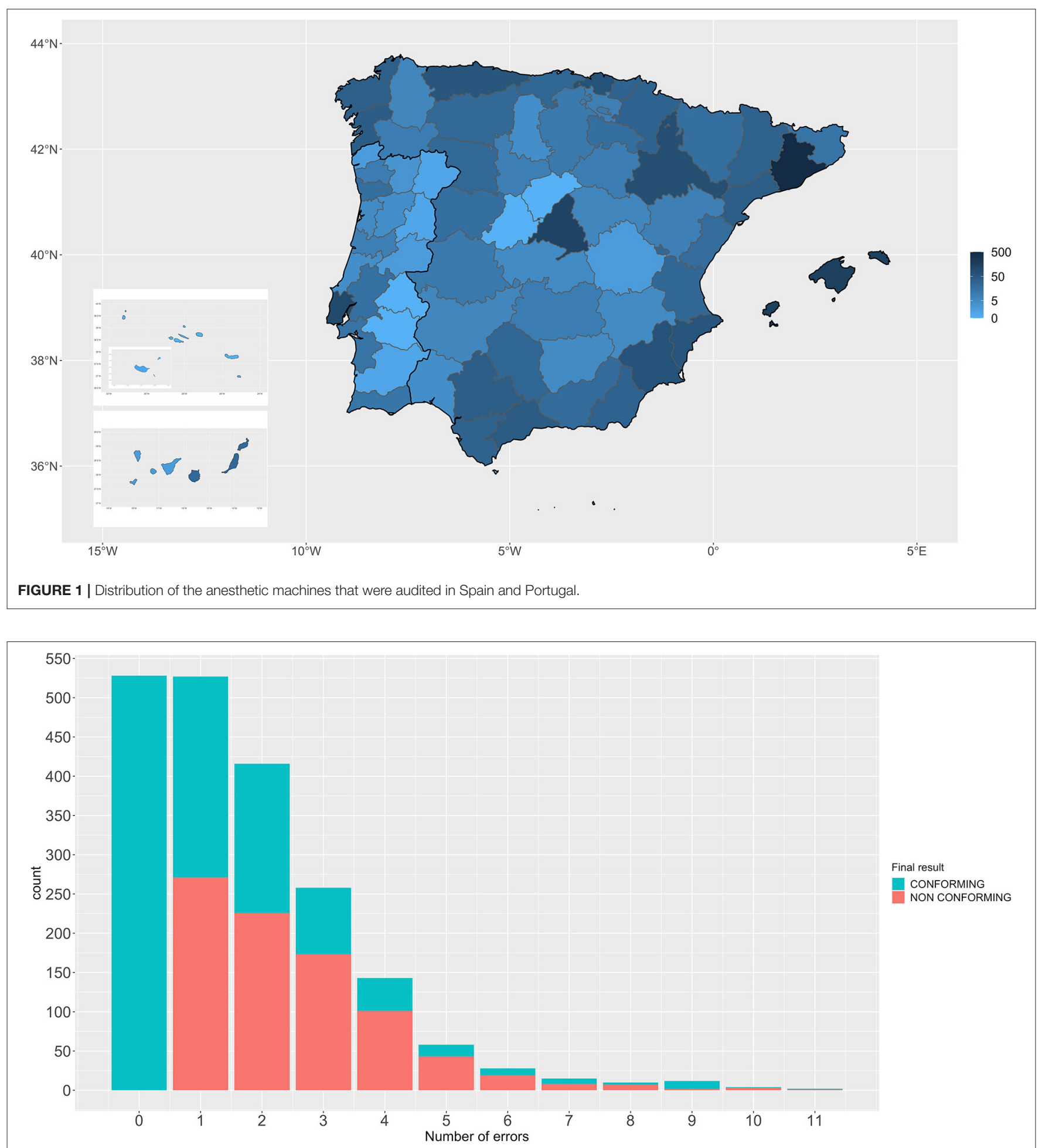

FIGURE 2 | Number of anesthetic machines repaired separated by the number of malfunctions found and their final classification as conforming or non-conforming.

conforming (Figure 2). In summary, at the end of the inspection, $53.3 \%$ of the machines were found to be conforming, while the remaining $42.7 \%$ were recommended that they were withdrawn from service until further repair. The percentages of malfunctions detected in the machine components are shown in Table 2 and Figure 3.

Out of the 2,001 machines, 1,407 used a concentrator as oxygen source, 485 an oxygen cylinder and 109 lack of an oxygen 
TABLE 2 | Percentage and number of malfunctions after the initial inspection of the different parts of the anesthetic machine, circuits, and scavenger.

\begin{tabular}{|c|c|c|c|}
\hline Item & Correct & Incorrect & $\%$ of malfunction \\
\hline Oxygen source & 1800 & 201 & 10.0 \\
\hline cylinder & 476 & 9 & 1.9 \\
\hline concentrator & 1226 & 181 & 12.9 \\
\hline Oxygen hose & 1938 & 63 & 3.1 \\
\hline Connections & 1862 & 139 & 6.9 \\
\hline Pressure gauge & 1808 & 193 & 9.6 \\
\hline Flowmeter & 1922 & 79 & 3.9 \\
\hline Vaporizer & 1656 & 653 & 28.3 \\
\hline isoflurane & 1454 & 540 & 27.1 \\
\hline sevoflurane & 202 & 113 & 35.9 \\
\hline Oxygen emergency valve & 1931 & 70 & 3.5 \\
\hline Fresh gas output & 1916 & 85 & 4.2 \\
\hline Inspiratory valve & 1909 & 92 & 4.6 \\
\hline Expiratory valve & 1884 & 117 & 5.8 \\
\hline Corrugated tubes & 1858 & 143 & 7.1 \\
\hline APL valve & 1777 & 224 & 11.2 \\
\hline Negative pressure valve & 1949 & 52 & 2.6 \\
\hline Canister & 1498 & 503 & 25.1 \\
\hline Reservoir bags & 1774 & 227 & 11.3 \\
\hline Mapleson E system & 771 & 211 & 21.5 \\
\hline Mapleson D system & 334 & 18 & 5.1 \\
\hline Mapleson A system & 642 & 75 & 10.5 \\
\hline Scavenger & 1243 & 758 & 37.9 \\
\hline
\end{tabular}

source, which were mobile secondary equipment. Most of the clinics used activated charcoal canisters as scavenger system and only seven veterinary clinics had an AGSS.

A total of 2,309 vaporizers were revised, 1,994 of which used isoflurane and 315 sevoflurane. In total, 1,656 were found to be correct while the remaining 653 were found to be incorrect (Tables 3, 4 and Figures 4, 5).

The classification tree analysis showed that the most important variables in the classification of the anesthetic machines as either conforming or non-conforming were, in descendent order, the scavenger system, the canister, the APL valve, the reservoir bag, the oxygen source, connections and the vaporizer (Figure 6). In the random forest analysis, the greatest decrease of the Gini index was found with the scavenger system and the canister, followed some way behind by the APL valve, source of oxygen, reservoir bag, vaporizer, connections, manometer, expiratory valve, and fresh gas output (Figure 7). The random forest algorithm correctly classified 100 and $96.1 \%$ of the conforming and non-conforming anesthetic machines, respectively.

\section{DISCUSSION}

This audit detected that $73.6 \%$ of the anesthetic machines were non-conforming. During revision, the inspector was able to solve the malfunction in-situ in $30.9 \%$ of the machines. A total of $27.1 \%$ of isoflurane and $35.9 \%$ of sevoflurane vaporizers were found to be non-conforming. Machine learning techniques showed that the most important variables in the classification of the anesthetic machines as either conforming or non-conforming were mostly the scavenger system and the canister, followed by the oxygen source, the expiratory and APL valves, the reservoir bags and the vaporizers.

In a study of 64 anesthetic machines in veterinary clinics in New Zealand, the percentage of malfunctions was as high as $91 \%$ (12). In this audit $73.6 \%$ of the machines were initially classified as non-conforming. This result could be considered comparable to the $91 \%$ due to the small sample size it included. Although 25 years have passed between both studies, the advancement in technology and equipment doesn't seem to be translated to significantly better results in regard to proper maintenance of anesthetic equipment.

The use of anesthetic equipment checklists is recommended by most human and veterinary anesthesia clinical guidelines (9-11, 14). Several human studies state that most of the complications arising from equipment malfunction are due to an inadequate machine check, especially between cases as opposed to at the beginning of the day $(17,18)$. It should be noted, however, that the use of checklists should not be intended to replace regular inspections by trained personnel, but rather complement it. This audit did not record the use of or compliance with such checklists and therefore the impact that the use of these may pose on the functioning of the equipment cannot be assessed. Nevertheless, the results of this audit may serve to highlight the importance of the use of checklists since most of the malfunctions detected, which led to classify the anesthetic machines as not-conforming, could have been identified and prevented by the daily use of in-house checklists. Since the routine implementation of a checklist, such as the internationally approved Association of Veterinary Anesthetists (AVA) one (19), could have avoided some of most common malfunctions detected, further audits that include the use of preanesthetic checklist are warranted.

The classification tree and the random forest analysis agreed in that malfunctions were usually found in the scavenger system, the canister, the APL valve, the reservoir bag, the oxygen source, connections, and the vaporizer. The algorithms obtained thereof may help to optimize the inspection of anesthetic machines. The component in which most problems were observed was the scavenger system, $37.9 \%$ of which were found to be non-conforming. Most malfunctions were due to the absence of a scavenger system or an exhausted activated charcoal canister. Chronic exposure to an environment contaminated with inhalational anesthetics can cause chronic toxicity in exposed personnel $(20,21)$. When evacuation systems are used, no study has been able to demonstrate that traces of anesthetic gases negatively affect operating room personnel (18). In fact, Spanish regulations establish a limit value-daily exposure (VLA-ED) of isoflurane and $\mathrm{N} 2 \mathrm{O}(22)$.

The second most frequent component to malfunction was the canister $(25.1 \%)$. Canisters require regular inspections, as the absorbent contained within must be changed when it is exhausted. Improper sitting of the canister, accumulation of dust 


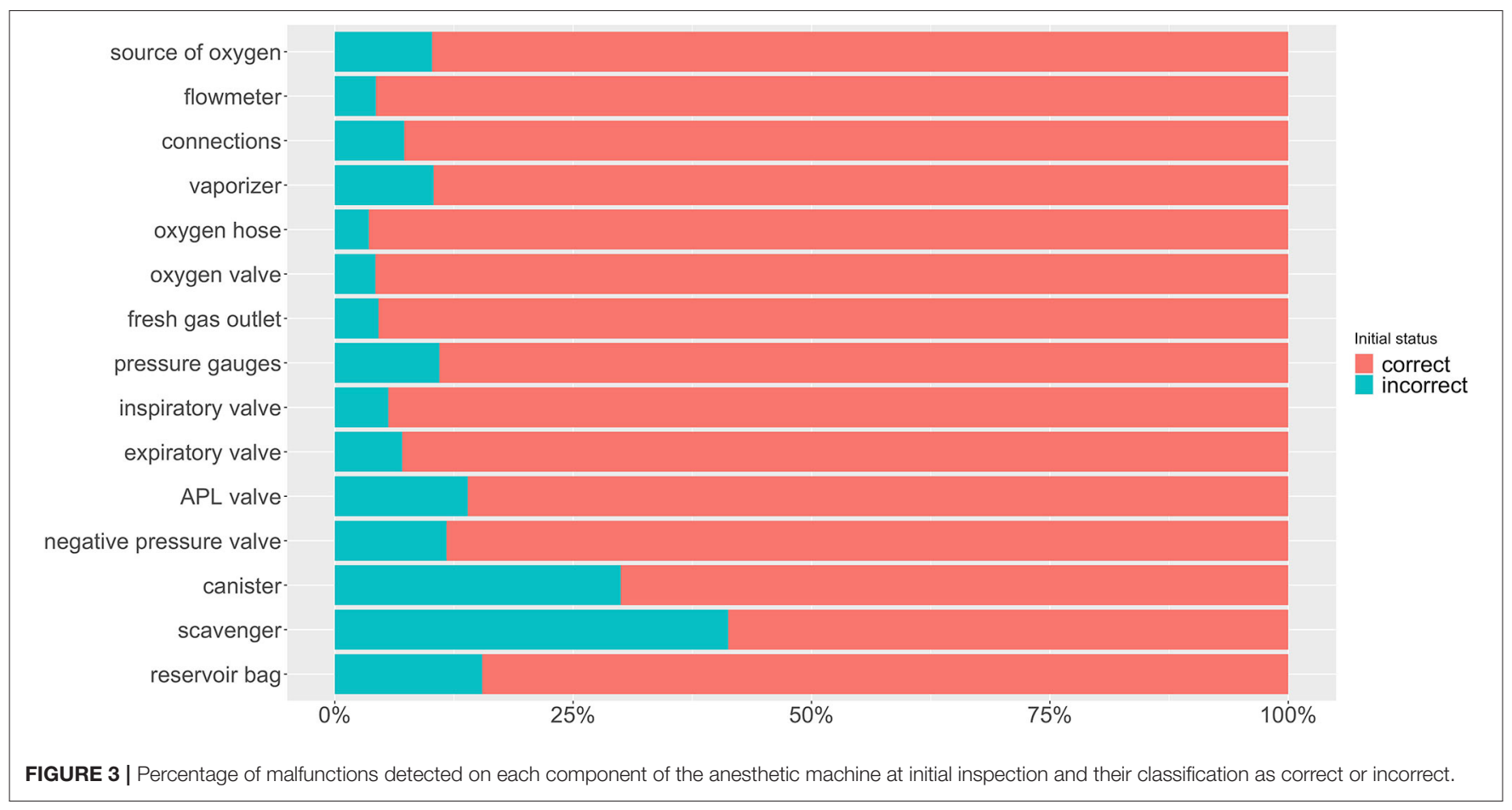

TABLE 3 | Percentage of isoflurane vaporizers that malfunction according to the position of the dial and the gas flow used.

\begin{tabular}{|c|c|c|c|c|c|c|c|c|c|c|c|c|}
\hline Error & \multicolumn{4}{|c|}{ Vaporizer $0.5 \%$} & \multicolumn{4}{|c|}{ Vaporizer 2\% } & \multicolumn{4}{|c|}{ Vaporizer 3\% } \\
\hline$(-20)$ to $(-10) \%$ & 10.2 & 8.8 & 9.6 & 10.4 & 5.0 & 3.9 & 2.8 & 2.7 & 3.1 & 2.3 & 1.8 & 1.9 \\
\hline$(-10)$ to $0 \%$ & 0 & 0 & 0 & 0 & 20.5 & 17.1 & 15.6 & 15.7 & 19.7 & 17.0 & 14.0 & 14.5 \\
\hline $0 \%$ & 36.7 & 34.7 & 34.7 & 35.6 & 20.8 & 19.9 & 17.8 & 20.9 & 13.8 & 11.1 & 11.9 & 13.3 \\
\hline $10-20 \%$ & 36.7 & 39.8 & 39.4 & 38.4 & 14.5 & 16.6 & 19.0 & 17.1 & 17.9 & 21.3 & 23.5 & 21.2 \\
\hline$<20 \%$ & 13.7 & 14.2 & 13.8 & 12.8 & 7.0 & 8.4 & 8.6 & 7.1 & 6.9 & 7.5 & 7.8 & 6.2 \\
\hline
\end{tabular}

L/min, liters per minute.

TABLE 4 | Percentage of sevoflurane vaporizers that malfunction according to the position of the dial and the gas flow used.

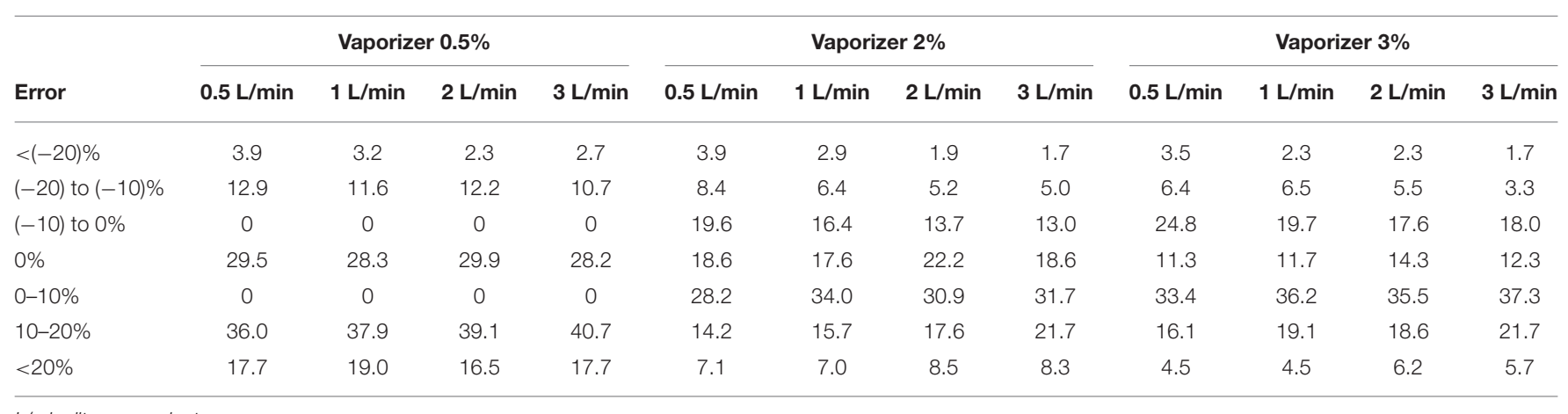

L/min, liters per minute. 


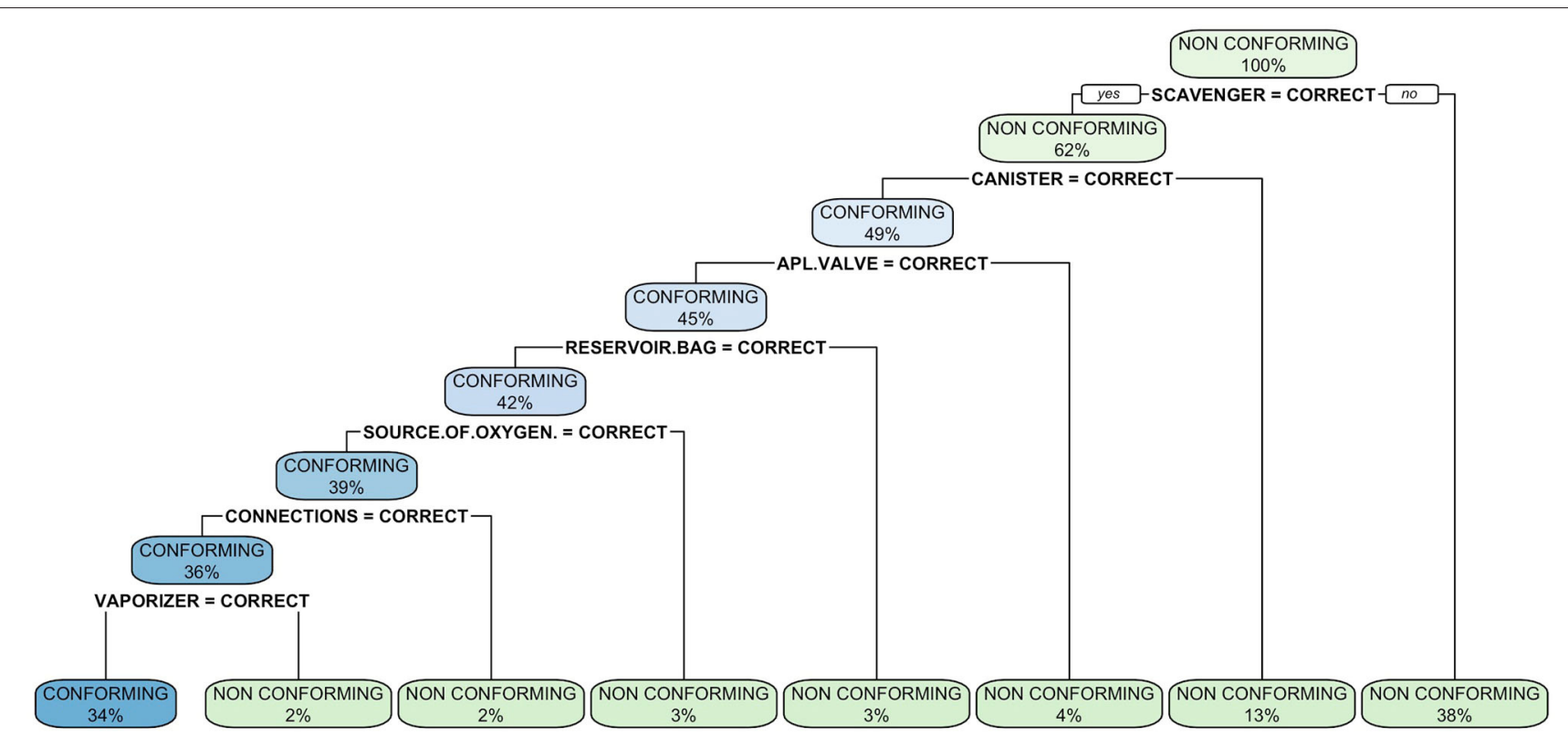

FIGURE 4 | Classification tree of malfunctions detected at inspection of anesthetic machines. The classification tree represents the different selection criteria or "decision nodes" used to predict the most correct classification of the total number of cases (represented at the root of the tree as a 100\%). As the data is classified in subsets, the percentage value represents the probability of a case of belonging to that data subset.

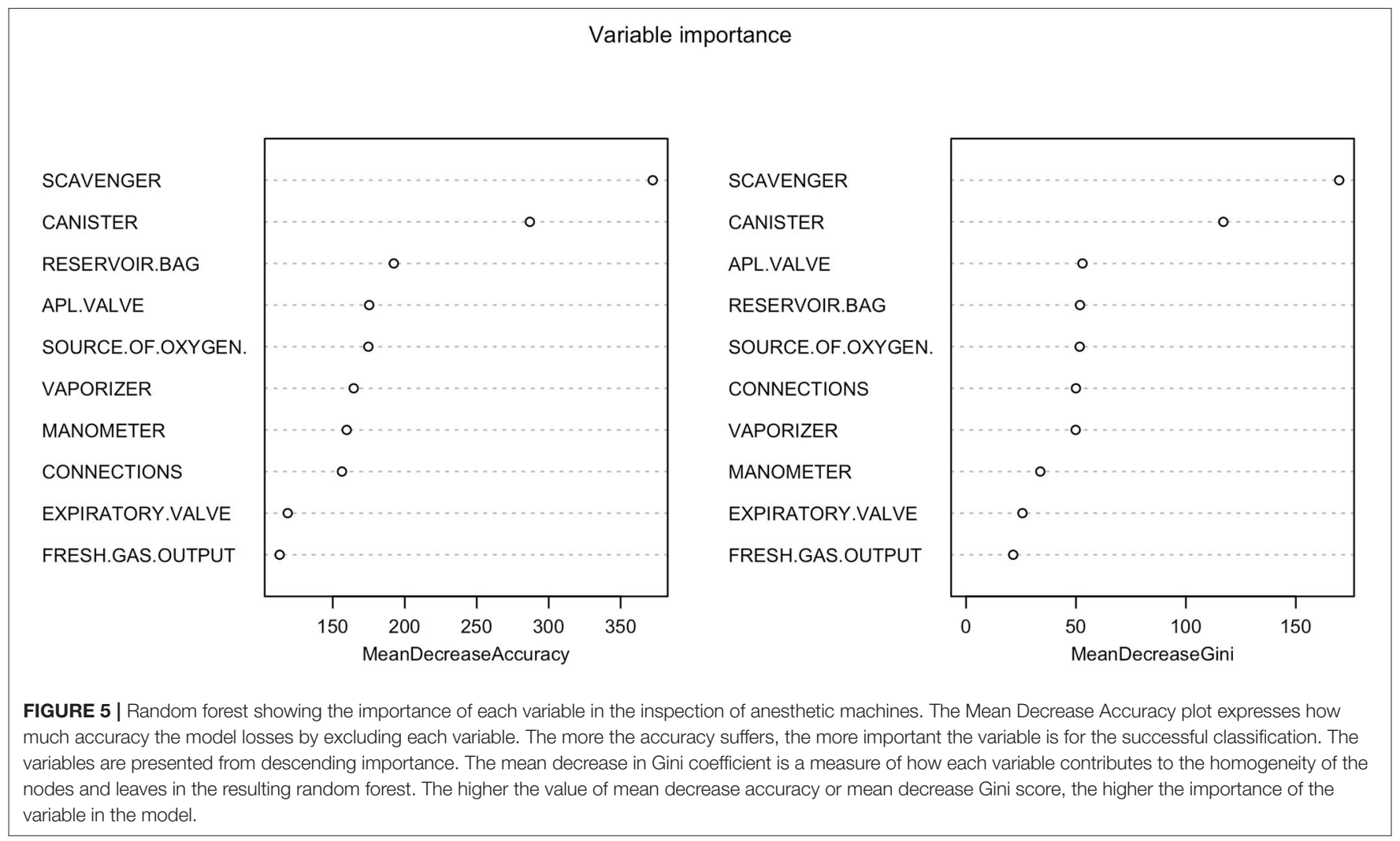

in the junctions, or malfunctioning of the absorbent may result in adverse events to the patient and personnel (1). This finding is in agreement with other studies stating that the canister could be one of the main sources of leaks in the anesthetic machine (23). 

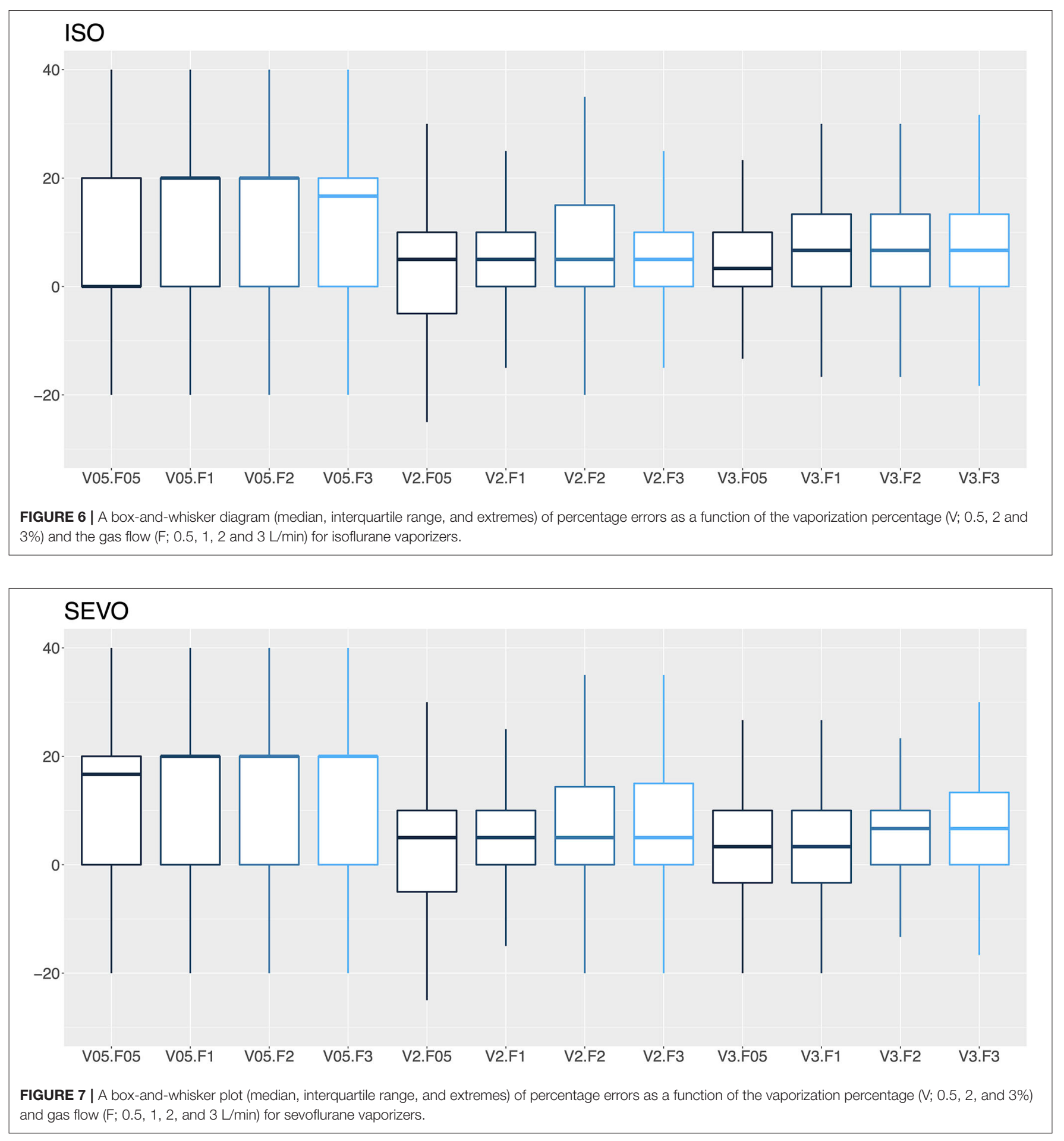

The reservoir bag was the third most frequent component to malfunction $(11.3 \%)$. In veterinary medicine, reusable latex, silicone or rubber bags are normally used. Over time, when exposed to high oxygen concentrations, the material loses its elasticity and becomes damaged, especially in the area where the bag is attached to the anesthesia breathing system (24). Reservoir bags should be checked regularly and replaced if leaks are detected. Additionally, Inspectors frequently reported lack of availability of varied reservoir bag sizes which poses a risk of overinflation when a reservoir bag smaller than the indicated one is used (25).

The fourth component that most frequently malfunctioned was the APL valve (11.2\%) and the failures detected could never be repaired in situ by the inspector. If the APL valve cannot be 
fully open, it may cause from a small increase in airway resistance to barotrauma. Conversely, if it cannot be fully closed, it may preclude positive pressure ventilation. This malfunction has been also frequently observed in humans (26).

The oxygen source failed in $10.0 \%$ of the machines. Malfunctions were recorded in only $1.9 \%$ of the cylinders, compared to $12.9 \%$ of the $\mathrm{O}_{2}$ concentrators. In recent years, the use of oxygen concentrators in veterinary anesthesia has become popular in Spain and Portugal due to their versatility and low cost and as an alternative to medicinal oxygen bottles. These devices concentrate ambient oxygen and provide $\mathrm{FiO}_{2}$ up to $95 \%$ (27). However, they do need regular maintenance and checking, especially of the $\mathrm{O}_{2}$ concentration and the fresh gas flow they provide. A concentrator malfunction can result in a hypoxic mixture, which can cause adverse effects to the patient, and even death (5).

The inspiratory and expiratory valves are two of the most important components of the circle system. Their malfunction can result in adverse effects such as rebreathing of expired air, respiratory collapse and barotrauma (1). Malfunctions were detected in 4.6 and $5.8 \%$ of the machines, respectively. Valves can break or become blocked by secretions or moisture and therefore, the availability of spare valves for each machine and regular inspection are recommended (28).

In this audit, $27.1 \%$ of the isoflurane vaporizers and $35.9 \%$ of the sevoflurane vaporizers had vaporization errors $>20 \%$ with flows of 2 and $3 \mathrm{~L} / \mathrm{min}$ and therefore required recalibration by a technical service. An error rate ranging from 12.8-14.2\% to $16.5-19.0 \%$ in isoflurane and sevoflurane vaporizers was observed, respectively. The VAMOS anesthetic gas analyzer has an accuracy of one decimal place and overestimates the error at low percentages of vaporization, which could be considered a limitation of the study. For example, if the vaporizer dial is set to $0.5 \%$ and the actual vaporization percentage is $0.55 \%$, the analyzer will display $0.6 \%$, which represents an error of $20 \%$. In this study, VAMOS was used because it can detect a $20 \%$ error. However, a more accurate analyzer would be required to evaluate the performance of the vaporizer at low percentages. In this audit, the minimal studied flow was $0.5 \mathrm{~L} / \mathrm{min}$ which is the minimal flow recommended for accurate vaporization (29). Therefore, low-flow techniques, which are highly recommended to reduce contamination and consumption of anesthetics and oxygen (30), require the use of gas analyzers that provide in real time the anesthetic concentration administered to the patient (29). Any increase or decrease in the vaporization percentage of inhalational anesthetics can lead to adverse events such as anesthetic overdose, hypotension, decreased cardiac output, respiratory depression or even intraoperative awakening (31).

\section{REFERENCES}

1. Dorsch J, Dorsch S. Understanding Anesthesia Equipment. 5th ed. Philadelphia, PA: Lippincott Williams \& Wilkins (2012). p. 1056.

2. Fasting S, Gisvold SE. Equipment problems during anaesthesia-are they a quality problem? Br. J. Anaesth. (2002) 89:825-31. doi: 10.1093/bja/aef276
Our study has several limitations. Firstly, there is a sample bias. This study was not randomized, since only veterinary clients that had a commercial relationship with Ecuphar Veterinaria SLU in Spain or Belphar Lda in Portugal have been included. Based on a total count of 6,228 and between 1,400 and 1,600 veterinary clinics present in Spain and Portugal in 2019 (32), respectively, we can estimate that in this study more than $9.2 \%$ of the Spanish clinics and at least $7.4 \%$ of the Portuguese clinics were included. However, the large sample size of analyzed machines and vaporizers could mitigate this limitation. Secondly, this was a retrospective study based on a review of reports compiled by a technical team of seven people. Although the training and technical criteria of the team were similar, a subjective component when it comes to finding equipment malfunctions may have also taken place. Thirdly, neither the private data of the clinics nor the equipment inspected were identified during this audit in such a way to allow traceability and therefore, some machines and vaporizers may have been inspected several times in different years. Further studies that keep track of the inspected equipment would be required to determine the effect that regular inspections have on their functioning over time.

In this study, most audited machines malfunctioned during the inspection and the inspector was able to repair a significant number of them in situ. In conclusion, a regular revision of anesthetic equipment by qualified personnel and the daily implementation of routine checklists are key to ensure proper functioning and to avoid adverse effects on the patient, personnel, and environment.

\section{DATA AVAILABILITY STATEMENT}

The raw data supporting the conclusions of this article will be made available by the authors, without undue reservation.

\section{AUTHOR CONTRIBUTIONS}

JR and LD contributed to the conception of the study, interpretation, drafted and revised the manuscript, and approved the final version. $\mathrm{CM}, \mathrm{AB}, \mathrm{AM}$, and $\mathrm{DL}$ contributed to the data acquisition, drafted and revised the manuscript, and approved the final version. All authors contributed to the article and approved the submitted version.

\section{ACKNOWLEDGMENTS}

The authors would like to thank Jorge Cristobal, Alejo Gila, and Andreia Oliveira for their technical support in data collection at various stages of this project. patients recorded in the French safety database in 2005-2006. Anesthesiology. (2010) 112:364-72. doi: 10.1097/ALN0b013e3181ca2e55

4. Cassidy CJ, Smith A., Arnot-Smith J. Critical incident reports concerning anaesthetic equipment: analysis of the UK National Reporting and 
Learning System (NRLS) data from 2006-2008*. Anaesthesia. (2011) 66:87988. doi: 10.1111/j.1365-2044.2011.06826x

5. Caplan RA, Vistica MF, Posner KL, Cheney FW. Adverse anesthetic outcomes arising from gas delivery equipment: a closed claims analysis. Anesthesiology. (1997) 87:741-8. doi: 10.1097/00000542-199710000-00006

6. Cantwell SL, Modell JH. Inadvertent severe hypercarbia associated with anesthesia machine malfunction in one cat and two dogs. J. Am. Vet. Med. Assoc. (2001) 219:1573-6-1551. doi: 10.2460/javma.2001.2191573

7. Mattson S, Kerr C, Dyson D. Anesthetic equipment fault leading to hypercapnia in a cat. Vet. Anaesth. Analg. (2004) 31:231-4. doi: 10.1111/j.1467-2987.2004.00136x

8. Langton S, Flaherty D, Pawson P, Auckburally A. A serious breathing system fault identified by capnography. Vet. Anaesth. Analg. (2010) 37:5812. doi: $10.1111 / j .1467-2995.2010 .00574 x$

9. Allweiler S, Heath RB. Commentary and Recommendations on Control of Waste Anesthetic Gases in the Workplace (2013) Available online at: https:// acvaa.org/wp-content/uploads/2019/05/Control-of-Waste-Anesthetic-GasRecommendations.pdf (accessed November 4, 2020)

10. McMillan M, Coppens P, Kronen PW, MacFarlane P, McMillan S, Pang D. Anaesthetic Safety Checklist Implementation Manual (2014). Available online at: https://ava.eu.com/wp-content/uploads/2015/11/AVA-Checklist-BookletFINAL-Web-copy.pdf (accessed November 4, 2020)

11. Hartle A, Anderson E, Bythell V, Gemmell L, Jones H, McIvor D, et al. Checking anaesthetic equipment 2012. Anaesthesia. (2012) 67:6608. doi: 10.1111/j.1365-2044.2012.07163x

12. Scuffham AM, Forsyth SF, Jones BR. A survey of anaesthetic equipment in veterinary practices in New Zealand. N. Z. Vet. J. (2011) 43:1620. doi: 10.1080/00480169.199535834

13. European Parliament. Regulation (EU) 2016/679 of the European Parliament and of the council of 27 April 2016 on the protection of natural persons with regard to the processing of personal data and on the free movement of such data, and repealing Directive 95/46/EC (General Data Protection Regulation). Official J. Eur. Union. (2016) L119:87-107.

14. Cassinello F, Ariño JJ, Ruibal AB, de la Pinta JC, de la Quintana FB, Espinosa ME, et al. Directrices de procedimientos de comprobación y validación (《chequeo») previos a la anestesia de la Sociedad Española de Anestesiología. Rev. Española de Anestesiología y Reanimación. (2012) 59:210-6. doi: 10.1016/j.redar.2012.03002

15. Hartsfield SM. Anesthesia equipment. In: Carroll GL, editor. Small Animal Anesthesia and Analgesia. Oxford: Blackwell Publishing (2008), p. 3-24

16. Chakravarti S, Basu S. Modern anaesthesia vapourisers. Ind. J. Anaesth. (2013) 57:464-71. doi: 10.4103/0019-5049120142

17. Bourgain JL, Coisel Y, Kern D., Nouette-Gaulain K, Panczer M. What are the main "'machine dysfunctions"' to know? Ann. Françaises d'Anesthésie et de Réanimation. (2014) 33:466-71. doi: 10.1016/j.annfar.2014.07744

18. McGregor DG. Occupational exposure to trace concentrations of waste anesthetic gases. Mayo Clin. Proc. (2000) 75:273-7. doi: 10.4065/75.3273

19. McMillan M, Coppens P, Kronen P, Mcfarlane P, McMillan S, Pang D. Anaesthetic Safety Checklist (2014). Available online at: https://ava.eu.com/ wp-content/uploads/2015/12/AVA-AnaestheticSafetyChecklist-FINAL-EUWEB-copy.pdf (accessed November 29, 2020).
20. Vaisman AI. Working conditions in the operating room and their effect on the health of anesthetists. Eksperimental'naia Khir. i Anesteziol. (1967) 12:44-9.

21. Buring JE, Hennekens $\mathrm{CH}$, Mayrent SL. Health experiences of operating room personnel. Anesthesiology. (1985) 62:32530. doi: 10.1097/00000542-198503000-00018

22. INSST. Límites de exposición profesional para agentes químicos en España 2019 (2019) Available online at: https://www.insst.es/documents/94886/188493/ L\%C3\%ADmites\$+\$de\$+\$exposición\$+\$profesional\$+\$para\$+\$agentes\$+ \$qu\%C3\%ADmicos\$+\$2019/7b0b9079-d6b5-4a66-9fac-5ebf4e4d83d1 (accessed October 29, 2020).

23. Umesh G, Jasvinder K, Sagarnil R. Leak in the breathing circuit: $\mathrm{CO}_{2}$ absorber and human error. J. Clin. Monitor Comp. (2010) 24:1434. doi: 10.1007/s10877-010-9223-7

24. Malamed SF. Inhalation sedation equipement. In: Malamed SF, editor. Sedation: A Guide to Patient Management. St. Louis: Elsevier (2017). p. 203-226. doi: 10.1016/B978-0-323-05680-900017-5

25. Thomas JA, Lerche P. Anesthesia and Analgesia for Veterinary Technicians. 5th ed. St. Louis: Mosby (2016). p. 456.

26. Oprea AD, Ehrenwerth J, Barash PG. A case of adjustable pressure-limiting (APL) valve failure. J. Clin. Anesth. (2011) 23:58-60. doi: 10.1016/j.jclinane.2009.10020

27. Burm AGL. Occupational hazards of inhalational anaesthetics. Best Pract. Res. Clin. Anaesth. (2003) 17:147-61. doi: 10.1053/bean.20030271

28. Mostafa S, Hall I. Expiratory valves and anaesthetic reservoir bags. Anaesthesia. (1985) 40:55-61. doi: 10.1111/j.1365-2044.1985.tb10504x

29. Nunn G. Low-flow anaesthesia. Contin. Educ. Anaesth. Crit. Care Pain. (2008) 8:1-4. doi: 10.1093/bjaceaccp/mkm052

30. Jones RS, West E. Environmental sustainability in veterinary anaesthesia. Vet. Anaesth. Analg. (2019) 46:409-20. doi: 10.1016/j.vaa.2018. 12008

31. Duke-Novakovski T, de Vries M, Seymour C. BSAVA Manual of Canine and Feline Anaesthesia and Analgesia. New York, NY: John Wiley \& Sons (2015). p. 464.

32. Mercader P. La clínica veterinaria española 2019. (2019) Available online at: https://axoncomunicacion.net/wp-content/uploads/2020/01/InfografiaVMS-2019.pdf (accessed November 4, 2020).

Conflict of Interest: The authors declare that this study received funding from Ecuphar Veterinaria SLU and Belphar Lda. The funders were not involved in the study design, collection, analysis, interpretation of data, the writing of this article or the decision to submit it for publication.

The handling editor declared a past co-authorship with one of the authors JR.

Copyright (๑) 2020 Redondo, Domenech, Mateu, Bañeres, Martínez and Lopes. This is an open-access article distributed under the terms of the Creative Commons Attribution License (CC BY). The use, distribution or reproduction in other forums is permitted, provided the original author(s) and the copyright owner(s) are credited and that the original publication in this journal is cited, in accordance with accepted academic practice. No use, distribution or reproduction is permitted which does not comply with these terms. 